\title{
Correction to: Predicting behavioral competencies automatically from facial expressions in real-time video-recorded interviews
}

\author{
Yu-Sheng Su ${ }^{1} \cdot$ Hung-Yue Suen ${ }^{2}\left(\mathbb{D} \cdot\right.$ Kuo-En Hung $^{2}$
}

Published online: 16 March 2021

○) Springer-Verlag GmbH Germany, part of Springer Nature 2021

Correction to: Journal of Real-Time Image Processing https://doi.org/10.1007/s11554-021-01071-5

In the original publication of the article, the third author name has been incorrectly published as "Ku-En Hung". The correct name should be "Kuo-En Hung".

The original article has been corrected.

Publisher's Note Springer Nature remains neutral with regard to jurisdictional claims in published maps and institutional affiliations.

The original article can be found online at https://doi.org/10.1007/ s11554-021-01071-5.

Hung-Yue Suen

collin.suen@ntnu.edu.tw

$\triangle$ Kuo-En Hung

kuanntw@gmail.com

1 Department of Computer Science and Engineering, National

Taiwan Ocean University, Keelung City, Taiwan

2 Department of Technology Application and Human

Resource Development, National Taiwan Normal University,

Taipei City, Taiwan 